\title{
Analyses of the mechanical properties and microstructure of bamboo-epoxy composites
}

\author{
F. G. SHIN \\ Department of Applied Physics, Hong Kong Polytechnic, Kowloon, Hong Kong
}

X.- J. XIAN, W.-P. ZHENG

Institute of Mechanics, Academia Sinica, Beijing, Republic of China

M. W. YIPP

Department of Applied Biology and Chemical Technology, Hong Kong Polytechnic, Kowloon, Hong Kong

Bamboo reinforced epoxy possesses reasonably good properties to warrant its use as a structural material, and is fabricated by utilizing bamboo, an abundant material resource, in the technology of fibre composites. Literature on bamboo-plastics composites is rare.

This work is an experimental study of unidirectional bamboo-epoxy laminates of varying laminae number, in which tensile, compressive, flexural and interlaminar shear properties are evaluated. Further, the disposition of bamboo fibre, the parenchymatous tissue, and the resin matrix under different loading conditions are examined. Our results show that the specific strength and specific modulus of bamboo-epoxy laminates are adequate, the former being 3 to 4 times that of mild steel. Its mechanical properties are generally comparable to those of ordinary glass-fibre composites. The fracture behaviour of bamboo-epoxy under different loading conditions were observed using both acoustic emission techniques and scanning electron microscopy. The fracture mode varied with load, the fracture mechanism being similar to glass and carbon reinforced composites. Microstructural analyses revealed that natural bamboo is eligibly a fibre composite in itself; its inclusion in a plastic matrix will help solve the problems of cracking due to desiccation and bioerosion caused by insect pests. Furthermore, the thickness and shape of the composite can be tailored during fabrication to meet specific requirements, thereby enabling a wide spectrum of applications.

\section{Introduction}

Bamboo is an abundant natural resource in Asia and South America, and has been used traditionally for fabrication of village houses and home utensils, without fully exploiting its potential as a structural material. Massive use of bamboo in this direction appears possible if it is deployed as a reinforcing constituent in a composite material. For example, bamboo-epoxy laminates can be made into specific sizes and shapes, preserving the natural microstructural properties yet overcoming the limitations of its cylindrical macrostructure. As a further advantage, cracking and bioerosion caused by insect pests is also prevented. The application potential of this composite in construction is considerable.

Research in the last twenty years has focused on mechanical properties of fibre-glass and carbon reinforced composites [1-3]. The production of these composites of excellent mechanical properties is complex and costly, thus restricting their current use to the newer industries. Some recent work on natural fibre reinforced composites concern wood and jute fibres $[4$, 5]. Lakkad et al. [6] and Jindal [7] reported on the mechanical properties of bamboo, and Pako- tiprapha et al. [8] reported on the reinforcement of cement by bamboo fibres. There has been little work on the mechanical properties and fracture mechanisms of bamboo-epoxy composites under different loading conditions. In particular, the microscopic disposition of such materials has not been recorded.

This paper investigates the tensile, compressive, flexural and inter-laminar shear properties of bambooepoxy composites of varying lamina numbers. Observations made under scanning electron microscopy show the disposition of bamboo fibres, parenchyma cells and the epoxy matrix and their interfaces under different stresses. Longitudinal and cross-sections developed from rupture have also been investigated. Our studies indicate that the mechanical properties of bamboo-epoxy were comparable to ordinary fibreglass reinforced plastics. A specific strength 3 to 4 times that of mild steel was recorded. The acoustic emission technique was used to predict the occurrence of fracture and critical fracture. Our studies indicate that bamboo-epoxy composites can replace ordinary fibre-reinforced composites for construction and other purposes, with additional advantages in being comparatively lightweight and economic to produce. 


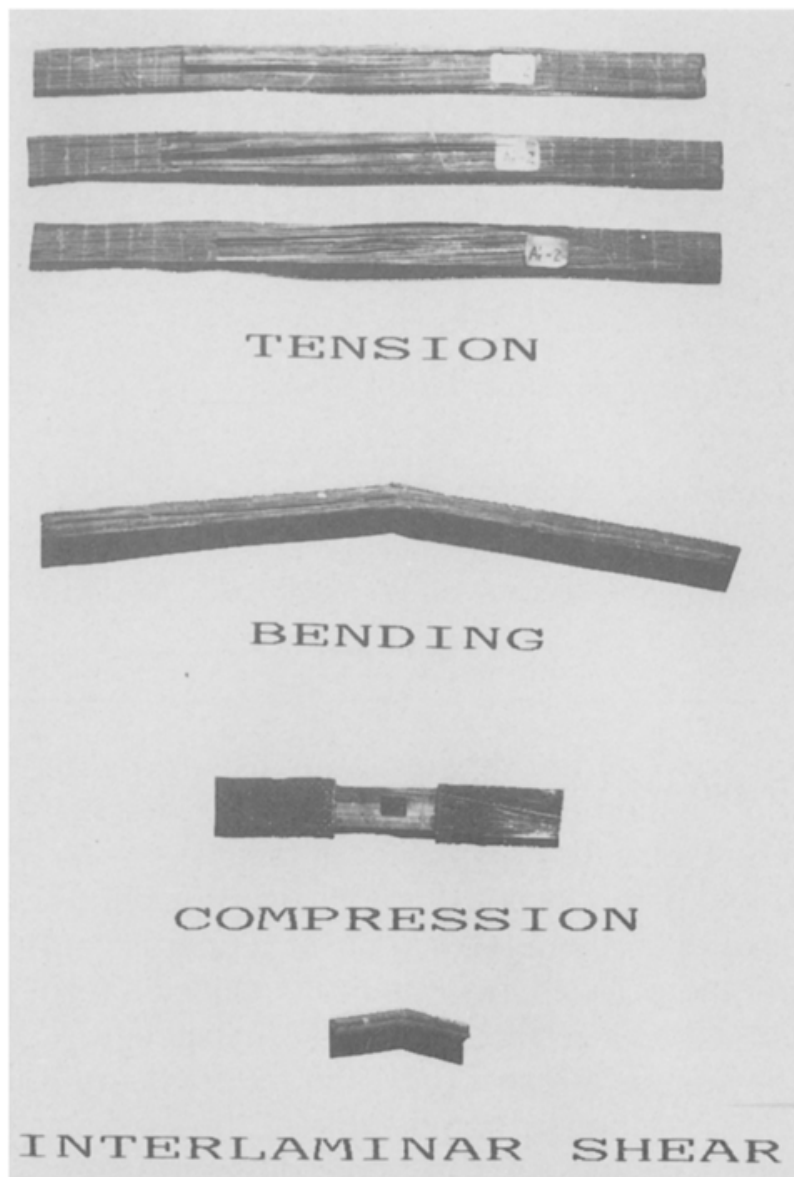

Figure I Specimens of bamboo-epoxy laminates used in the various experiments described in this paper.

\section{Materials and methods}

Bamboo materials tested belonged to the species Bambusa paravariabilis which is grown abundantly in Asia. Bamboo strips split longitudinally from internodal sections of a culm were pressed by rolling between a pair of steel cylinders and embedded in an epoxy matrix. Laminates of the composite material were produced following the method in [9], each lamina being approximately $1 \mathrm{~mm}$ thick. Test samples were of three layers $\left(A_{3}\right)$, five layers $\left(A_{5}\right)$ and seven layers $\left(A_{7}\right)$, all consisting of unidirectional fibres (Fig. 1). Specimen dimensions are recorded in Table I. The tensile, compressive, flexural and interlaminar shear properties were investigated on a macroscopic scale by means of an Instron 1195 universal testing machine. A crosshead speed of $1 \mathrm{~mm} \mathrm{~min}^{-1}$ was applied and load-displacement curves were generated for each

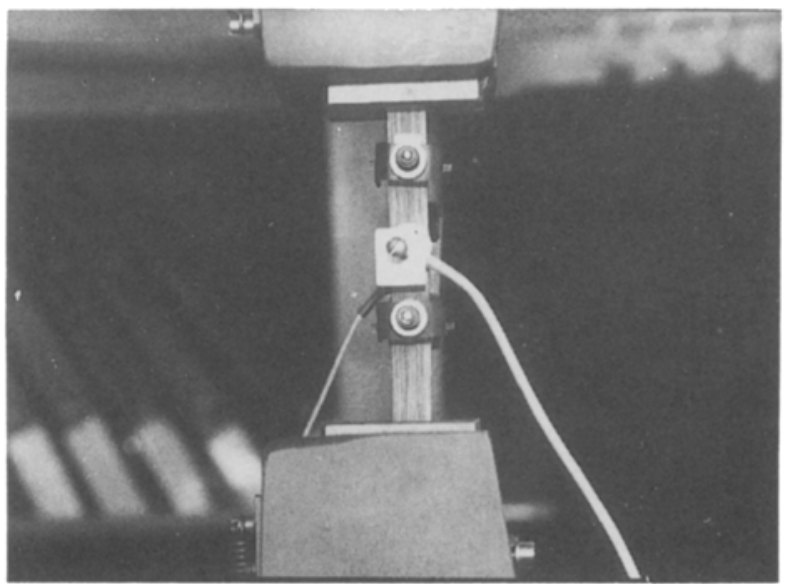

Figure 2 The acoustic-emission recorder (SFS-4) used to monitor fracture formation in macroscopic laminate specimens.

test. Poisson ratios were determined using strain gauges applied longitudinally and transversely. The results of these tests are presented in Table I.

Fracture behaviour of test laminates under stress were observed using an SFS-4 acoustic emission recorder (Fig. 2). A Hitachi S570 scanning electron microscope was used to observe the behaviour of laminates subjected to tensile and compressive stresses (Fig. 3). Dynamic SEM micrographs were taken for further analyses of fracture mode.

\section{Macroscopic mechanical properties of bamboo-epoxy}

3.1. Tensile properties

Basically, tensile load increased linearly with increasing strain until the point of ultimate load, when bamboo fibres underwent breakage exhibiting brittle fracture. At this point the $\sigma-\varepsilon$ curve showed sharp, staggered decreases (Fig. 4). Partial damage occurred in some specimens when the tensile load reached $85 \%$ of ultimate stress. This resulted in slight changes in the actual load, and was the point at which maximum acoustic emissions occurred (Fig. 9). The tensile strength and tensile modulus of unidirectional bambooepoxy composites were considerable. Averaging over $\mathrm{A}_{3}, \mathrm{~A}_{5}$ and $\mathrm{A}_{7}$, the mean $\bar{\sigma}_{\mathrm{t}}$ strength was $203 \mathrm{MPa}$, modulus $\bar{E}_{\mathrm{t}}$ was $61 \mathrm{GPa}$, and Poisson ratio $\bar{v}$ was 0.38 . The mechanical properties of the various laminates are given in Table I. Increase in lamina number was accompanied by a decrease in tensile strength. This was due to the increasing thickness of test laminates

TABLE I The dimensions and mechanical properties of bamboo-epoxy test laminate specimens

\begin{tabular}{|c|c|c|c|c|c|c|c|c|c|c|c|}
\hline \multirow[t]{2}{*}{ Lamina number } & \multirow{2}{*}{$\begin{array}{l}\text { Dimensions } \\
w \times t \\
\left(\mathrm{~mm}^{2}\right)\end{array}$} & \multicolumn{3}{|c|}{ Tensile stress } & \multicolumn{3}{|c|}{ Compressive stress } & \multicolumn{2}{|c|}{ Bending stress } & \multicolumn{2}{|c|}{ Interlaminar shear } \\
\hline & & $\begin{array}{l}\sigma_{\mathrm{t}} \\
(\mathrm{MPa})\end{array}$ & $\begin{array}{l}E_{1} \\
\text { (GPa) }\end{array}$ & $v$ & $\begin{array}{l}\sigma_{\epsilon} \\
(\mathrm{MPa})\end{array}$ & $\begin{array}{l}E_{\mathrm{c}} \\
(\mathrm{GPa})\end{array}$ & $v$ & $\begin{array}{l}\sigma_{\mathrm{b}} \\
(\mathrm{MPa})\end{array}$ & $\begin{array}{l}E_{\mathrm{b}} \\
(\mathrm{GPa})\end{array}$ & $\begin{array}{l}\tau_{13} \\
(\mathrm{MPa})\end{array}$ & $\begin{array}{l}G_{13} \\
(\mathrm{MPa})\end{array}$ \\
\hline Three layers $\left(\mathrm{A}_{3}\right)$ & $12.6 \times 3$ & 243 & 45 & 0.30 & 129 & 24.9 & 0.375 & 255 & 24.9 & 10.5 & 610 \\
\hline Five layers $\left(A_{5}\right)$ & $12.6 \times 5$ & 189 & 76 & 0.37 & 59 & 25.4 & - & 208 & 19.3 & 12.4 & 768 \\
\hline Seven layers $\left(\mathrm{A}_{7}\right)$ & $12.6 \times 7$ & 178 & 63 & 0.48 & 90 & 33.4 & - & 245 & 16.4 & 16.8 & 877 \\
\hline Mean & $63\left(\mathrm{~mm}^{2}\right)$ & 203 & 61 & 0.38 & 93 & 27.9 & 0.375 & 235 & 20.2 & 13.2 & 752 \\
\hline
\end{tabular}

Length of testing material: For tension and flexure :200 mm Specimen width : $w$

For thin plate compression : $100 \mathrm{~mm}$ Specimen thickness : $t$

For direct compression $: 25 \mathrm{~mm}$

For interlaminar shear $: 40 \mathrm{~mm}$ 


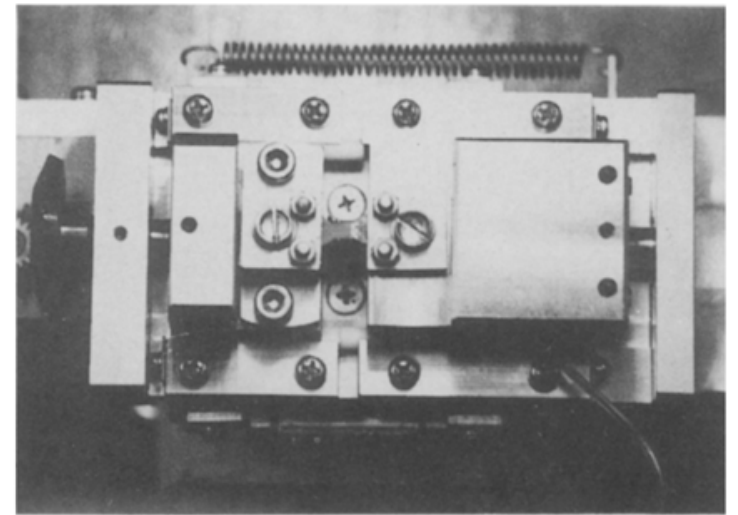

Figure 3 The attachment device to a Hitachi SEM S570, used for microscopic observations of laminates under tensile and compressive stresses.

with a corresponding increase in interlaminar voids. Poisson ratio and Young's modulus both increased as lamina number increased, with $E$ maximum occurring in $\mathrm{A}_{5}$ laminates. This is possibly because the decrease in longitudinal strain is greater than decrease in tensile strength. Tensile fracture of unidirectional bambooepoxy is mainly longitudinal cracking in the same orientation as the fibres (Fig. 1). (Some thick specimens failed at the clamped portion due to stress concentration; this factor is partially responsible for the decrease in tensile strength with increasing thickness.)

\subsection{Compressive properties}

Compressive properties were investigated using $A_{3}$ laminates. The thin plate compression experimental set-up is shown in Fig. 5, which is modified from ASTM D3410 standards. To ensure that fractures occurred in the middle portion of the test laminate, the two ends were reinforced with aluminium tabs (Fig. 1). The test laminate was aligned with the help of a pair of longitudinal strain gauges attached to the sides, and its position adjusted until the gauges showed identical strain to guarantee the absence of bending moment.

Maximum compressive strength was observed in $\mathrm{A}_{3}$ laminates, being $129 \mathrm{MPa}$. Its compressive modulus $\left(E_{\mathrm{c}}\right)$ was $25.9 \mathrm{GPa}$, which is less than its tensile modulus. The Poisson ratio $v$ was 0.375 .

Compressive loads below $93 \%$ of the fracture load

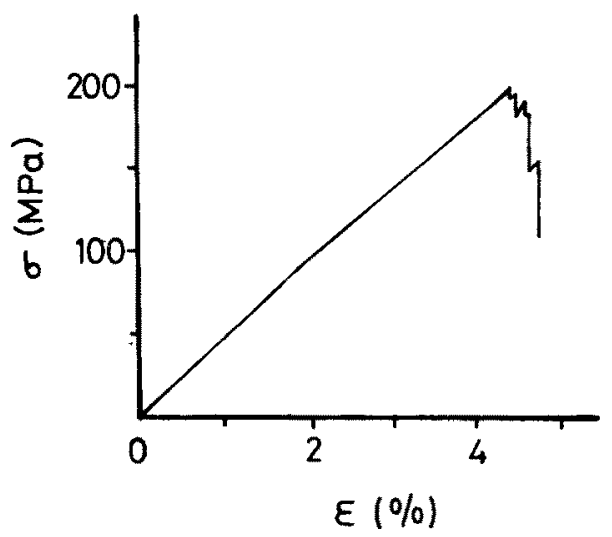

Figure $4 \mathrm{~A}$ stress--strain curve for an $\mathrm{A}_{5}$ bamboo-epoxy laminate specimen under tensile stress.

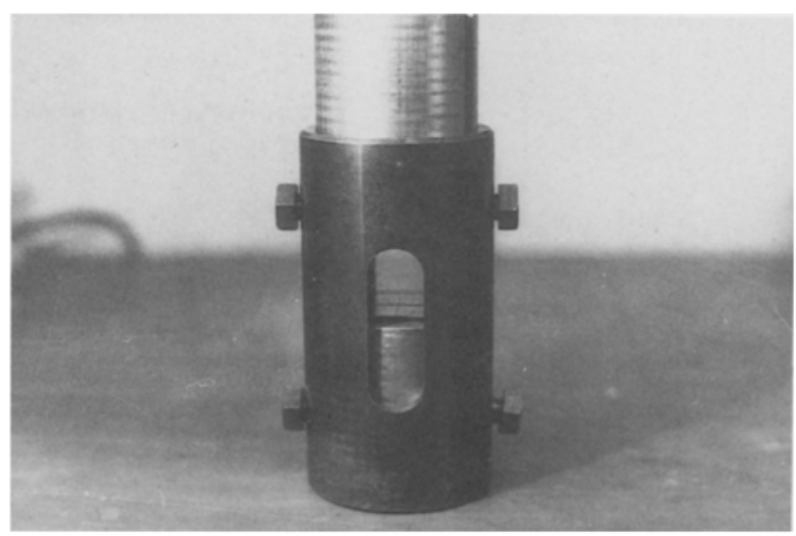

Figure 5 The experimental setup for thin plate compression tests.

generated a linear stress-strain relationship. During fracture, the compressive load on the test laminate rapidly decreased, until at two-thirds of the fracture load, when large deformation and buckling occurred, finally resulting in total destruction (Fig. 6).

The thicker $A_{5}$ and $A_{7}$ test laminates were compressed directly. The major damage was due to delamination, although some specimens showed compressive damage at the ends. These laminates had weaker compressive strength, $\bar{\sigma}_{\mathrm{c}}$ being $74.6 \mathrm{MPa}$ and $\bar{E}_{\mathrm{c}}$ being $29.4 \mathrm{GPa}$ when averaged over $A_{5}$ and $A_{7}$ (Table I). A linear followed by a non-linear segment was recorded in the stress-strain curve, but the transition between the two segments occurred earlier than in $\mathrm{A}_{3}$ laminates under thin plate compression, and fell between 60 and $80 \%$ of $P_{\mathrm{u}}$. This was caused by partial damage at the ends of the test laminates.

\subsection{Flexural properties}

Specimens were tested by three-point bending. The load-displacement curve showed an early linear segment, followed by a non-linear segment beyond $50 \%$ of fracture load until ultimate strength was applied. Following that, an irregular, staggered decrease in load was observed (Fig. 7). This can be attributed to a demonstration of strength in the respective laminae. The mean flexural strength $\bar{\sigma}_{\mathrm{b}}$ was $235 \mathrm{MPa}$ and the flexural modulus $\bar{E}_{\mathrm{b}} 20.2 \mathrm{GPa}$

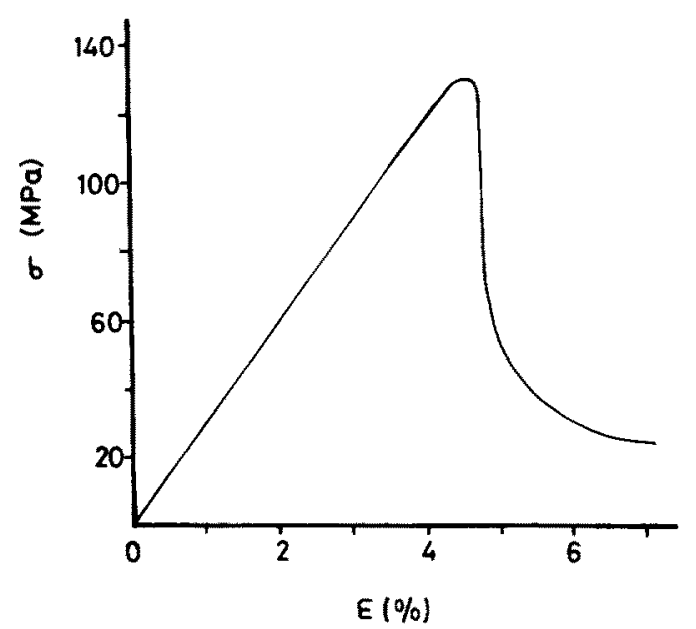

Figure 6 The stress-strain curve for an $\mathrm{A}_{3}$ bamboo-epoxy laminate specimen under compressive stress. 


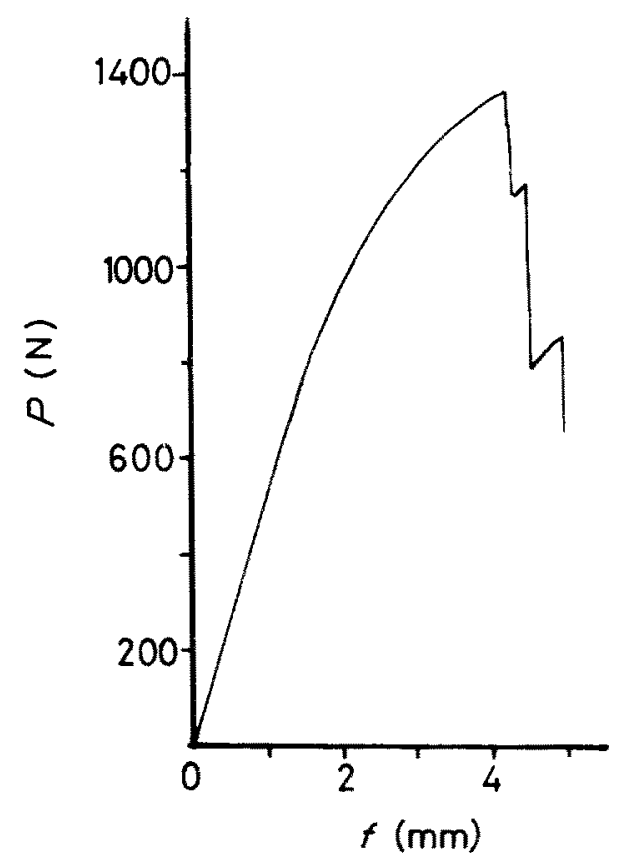

Figure 7 A typical load-displacement curve for a bamboo-epoxy laminate specimen under three-point bending.

(Table I). Bending fractures concentrated in the middle of the test laminate where load was applied.

\subsection{Interlaminar shear properties}

Interlaminar shear modulus $G_{13}$ was determined by five-point bending (three-point bending with extended specimen)

$$
G_{13}=\frac{P a}{2 w t f_{s}} \quad f_{\mathrm{s}}=f_{1}-f_{2}
$$

where $P$ is load increment as measured from preload, $a$ the half of the span length, $f_{1}$ the deflection increment at mid span, $f_{2}$ the deflection increment at two ends, $w$ the specimen width and $t$ the specimen thickness.

The interlaminar shear strength $\tau_{13}$ was determined by short beam shear method

$$
\tau_{13}=\frac{3}{4} \frac{P_{u}}{w t}
$$

where $P_{\mathrm{u}}$ is the ultimate load.

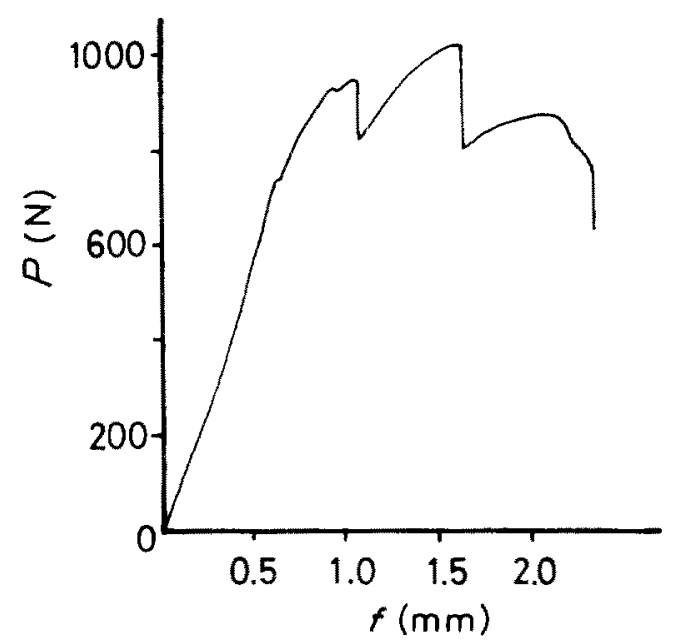

Figure 8 A typical load-displacement curve for a bamboo-epoxy laminate specimen under short beam shear.

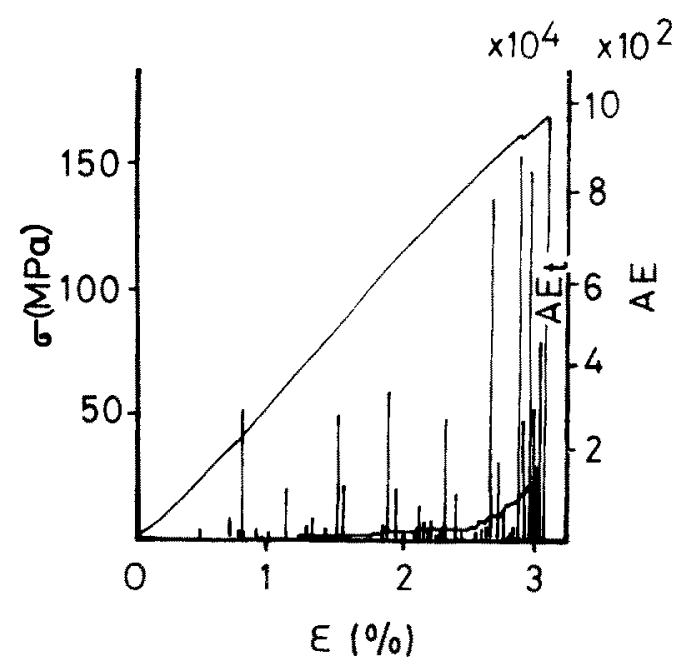

Figure 9 Acoustic emissions recorded from an $\mathrm{A}_{j}$ bamboo-epoxy laminate specimen under tensile stress.

The mean interlaminar shear strength $\bar{\tau}_{13}$ was 14.6 $\mathrm{MPa}$, and the mean interlaminar shear modulus $\bar{G}_{13}$ was $823 \mathrm{MPa}$. This low value is an inherent shortcoming of composite materials, and suggests that future research should focus on improving this drawback. The $\tau_{13}$ values of $A_{3}, A_{5}$ and $A_{7}$ laminates were $10.5,12.4$ and $16.8 \mathrm{MPa}$, respectively, the corresponding $G_{13}$ values being 610,768 and $877 \mathrm{MPa}$. A decrease in aspect ratio $(l / t)$ with increasing laminae numbers (span $l$ being fixed in the experiment) is responsible for the corresponding slight increase of interlaminar shear strength. Below 60 to $65 \%$ of breaking load, a linear relationship was recorded in the load-displacement curve (Fig. 8). Above this range, phased reductions in load were recorded as each succeeding interface underwent shear fracture, until breaking load was reached. As the lamina number increases, the number of reductions also increased.

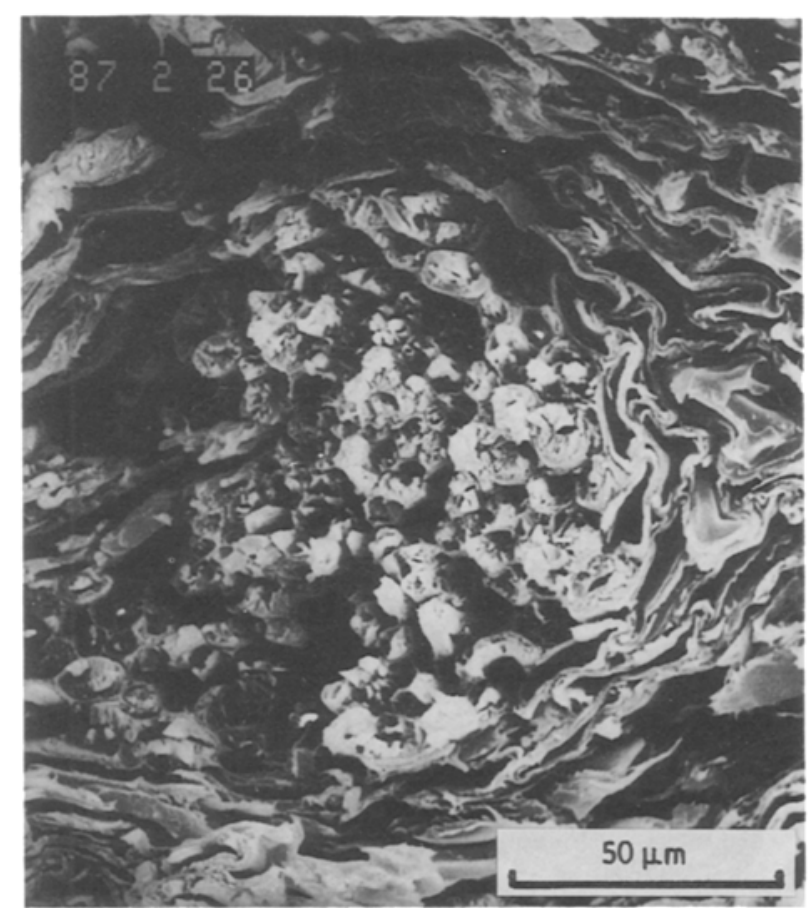

Figure 10 Cross-section of a bamboo-epoxy specimen showing tensile fracture in the vascular bundles. 


\section{Acoustic emission testing}

Using weighted ringdown as a parameter in the acoustic emission tests, the fracture behaviour of the test laminates was monitored by recording the acoustic emission (AE) signals and cumulative acoustic emissions $\left(\mathrm{AE}_{1}\right)$. Fig. 9 shows the typical $\mathrm{AE}$ recording of an $A_{7}$ sample under tensile stress. With stress levels at $7 \%$ of ultimate stress, small fractures in the epoxy matrix cause the emission of low amplitude $\mathrm{AE}$ signals. Stress levels at $24 \%$ of ultimate stress produced larger $\mathrm{AE}$ signals, indicating longitudinal cracking in the test specimen. Thereafter, large AE signals occurred at regular intervals between the smaller signals. At $79 \%$ ultimate stress, explosive signals were emitted, corresponding to tensile damage in some laminae. At $95 \%$ ultimate stress, maximum emissions were recorded, due to fracturing of bamboo fibres. AE signals continued to increase in amplitude and frequency until total collapse occurred.

Applying bending stress, the initial small amplitude and subsequent explosive signals occurred later than in tensile stress in terms of $\sigma_{\mathrm{utt}} \%$. This is because bending causes considerable deformation before ultimate fracture, and $\mathrm{AE}$ and $\mathrm{AE}_{1}$ were of greater magnitude than under tensile stress.

As the test specimen thickness increased, the initial small amplitude AE and explosive AE relative to ultimate bending stress took place progressively earlier. This was due to the greater abundance of interlaminar spaces with greater number of laminae, leading to earlier onset of fractures. Table II shows the AE values of three different kinds of test specimens under tensile and bending stress. The initial $\mathrm{AE}$ values were within 100, and the higher emissions were around 500 . Explosive emissions were above 1000 , while the maximum AE values approached 10000 . The occurrence of explosive AE indicated critical fracture, after which the fractures enlarged rapidly, leading to collapse of the test specimen.

Thus the occurrence of small amplitude AE can be used to predict the onset of fracturing in the epoxy matrix, and the occurrence of explosive AE of critical damage. The safety region for the use of this material is thus below the range of the explosive emissions.

\section{Micromechanical properties and analyses of microfractures}

Tensile and compression testing of the $\mathrm{A}_{3}$ bambooepoxy laminates were undertaken on the loading stage of the S-570 scanning electron microscope. The crosssection, surface and lateral aspect of the fractures were examined.

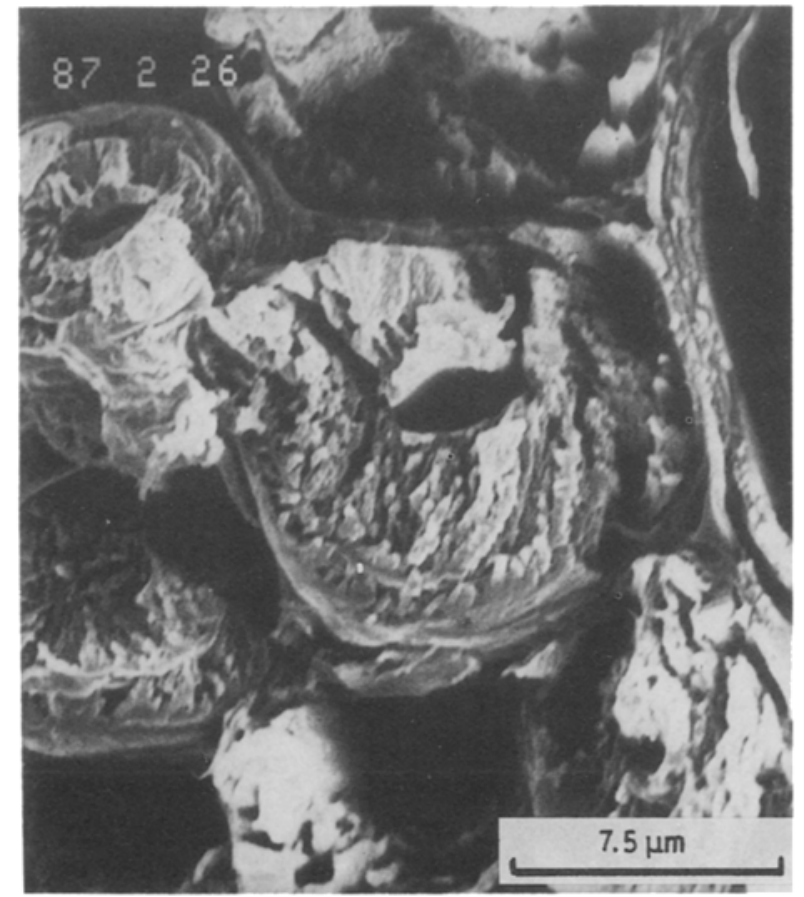

Figure 11 Crossmsection of vascular bundles in a bamboo-epoxy specimen, showing fracture surfaces.

\subsection{Microstructural studies of tension and compression induced fractures}

The compressive strength $\sigma_{\mathrm{c}}$ is $137 \mathrm{MPa}$, it is $106 \%$ of that recorded from thin plate compression in macroscopic observations. Furthermore, the fractures occurred in the middle by shear. The SEM compressive testing fixture and specimen are shown in Fig. 3. The results indicate that this self-designed set up is reasonable.

The SEM tensile testing set-up is seen in Fig. 3. Dumb-bell shaped test specimens were clamped at both ends, and subjected to tensile stress. The tensile strength $\sigma_{1}$ recorded was $130 \mathrm{MPa}$, and is about $65 \%$ of that observed in macroscopic samples, some fractures tended to occur towards the clamped ends of test samples owing to stress concentration there. Improvements in the experimental design should refine the accuracy of this measurement.

The crack on the fractograph induced by tensile stress did not penetrate through the specimen, and were not uniform. A cross-section of the fracture reveals sheaths of epoxy around a bundle of bamboo fibres (Fig. 10), and was different from fractures sustained in pure bamboo samples. Fig. 11 shows the fracture cross-sections of six vascular bundles in a bamboo-epoxy specimen. The thin walled parenchyma and their surrounding spaces are infiltrated with

TABLE II Acoustic emissions from bamboo-epoxy laminates under tensile and flexural stresses

\begin{tabular}{|c|c|c|c|c|c|c|c|c|c|c|c|c|c|c|c|c|}
\hline & \multicolumn{8}{|c|}{ Tensile stress } & \multicolumn{8}{|c|}{ Flexural stress } \\
\hline & \multicolumn{2}{|c|}{ Initial AE } & \multicolumn{2}{|c|}{ Large AE } & \multicolumn{2}{|c|}{ Explosive AE } & \multicolumn{2}{|c|}{ Ultimate AE } & \multicolumn{2}{|c|}{ Initial AE } & \multicolumn{2}{|c|}{ Large AE } & \multicolumn{2}{|c|}{ Explosive $\mathrm{AE}$} & \multicolumn{2}{|c|}{ Ultimate $\mathrm{AF}$} \\
\hline & $\sigma_{1} \%$ & $\mathrm{AE}$ & $\sigma_{1} \%$ & $\mathrm{AE}$ & $\sigma_{t} \%$ & $\mathrm{AE}$ & $\sigma_{1} \%$ & $\mathrm{AE}$ & $\sigma_{\mathrm{b}} \%$ & $\mathrm{AE}$ & $\sigma_{\mathrm{b}} \%$ & $\mathrm{AE}$ & $\sigma_{b} \%$ & $\mathrm{AE}$ & $\sigma_{b} \%$ & $\mathrm{AE}$ \\
\hline $\mathrm{A}_{3}$ & 21 & 25 & 35 & 445 & 96 & 3667 & 100 & 9818 & 30 & 196 & 58 & 585 & 79 & 990 & 90 & FS \\
\hline $\mathrm{A}_{5}$ & 13 & 77 & 26 & 287 & 73 & 1000 & 100 & $\mathrm{FS}$ & 24 & 34 & 32 & 579 & 82 & 900 & 100 & FS \\
\hline $\mathrm{A}_{7}$ & 7 & 10 & 24 & 31 & 79 & 752 & 95 & 889 & 19.1 & 52 & 24 & 364 & 74 & 964 & 98 & FS \\
\hline
\end{tabular}

FS full scale. 


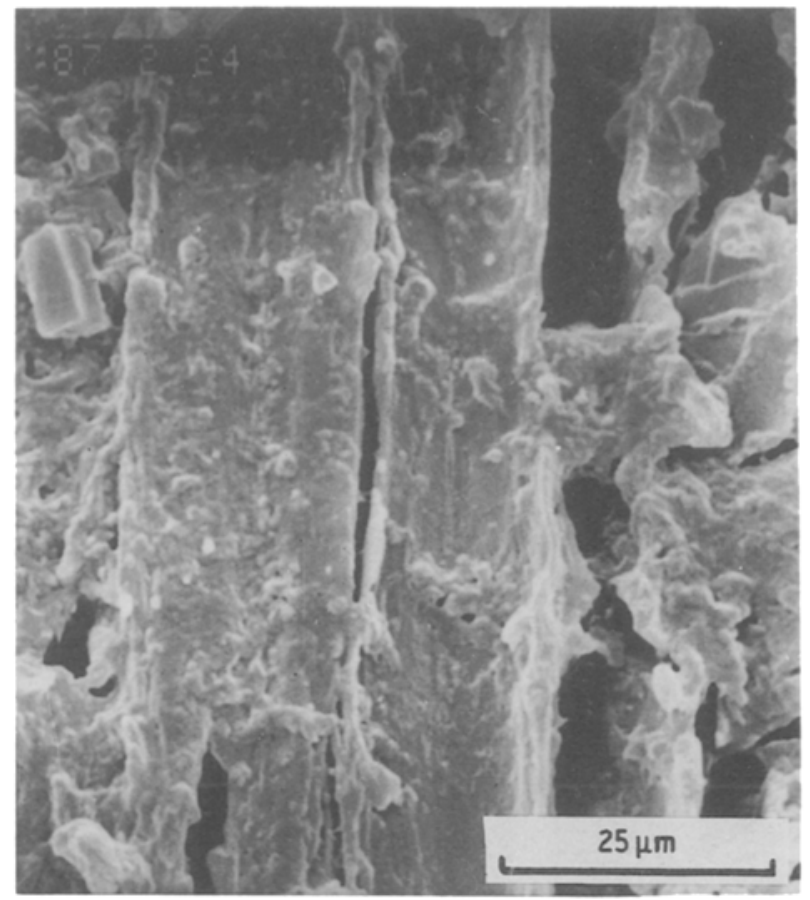

Figure 12 Lateral view through a bamboo-epoxy specimen, showing strong interface adhesion between the epoxy matrix and bamboo fibres.

epoxy, and due to the pressure received during sample preparation, deformation of the original fibre is evident.

In Fig. 12, the epoxy around some bamboo fibres show strong interface adhesion. Bamboo fibres appear slightly buckled and the bamboo-epoxy interface and epoxy-rich zones can be clearly seen in Fig. 13. Fig. 14 shows a bamboo fibre cracked by compression. The diameter of this fibre $(11 \mu \mathrm{m})$ is slightly less than natural bamboo fibres, demonstrating the compression experienced during sample preparation. Epoxy can be found on the surface, and the compression induced

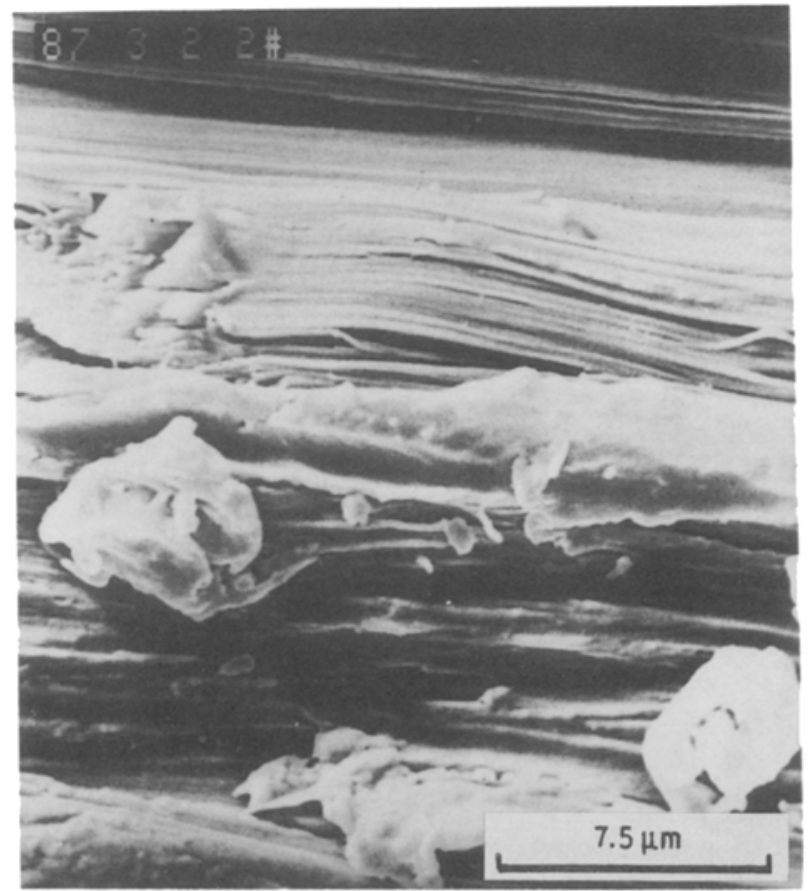

Figure 13 Lateral view of a bamboo-epoxy specimen showing slight buckling of bamboo fibres under compression.

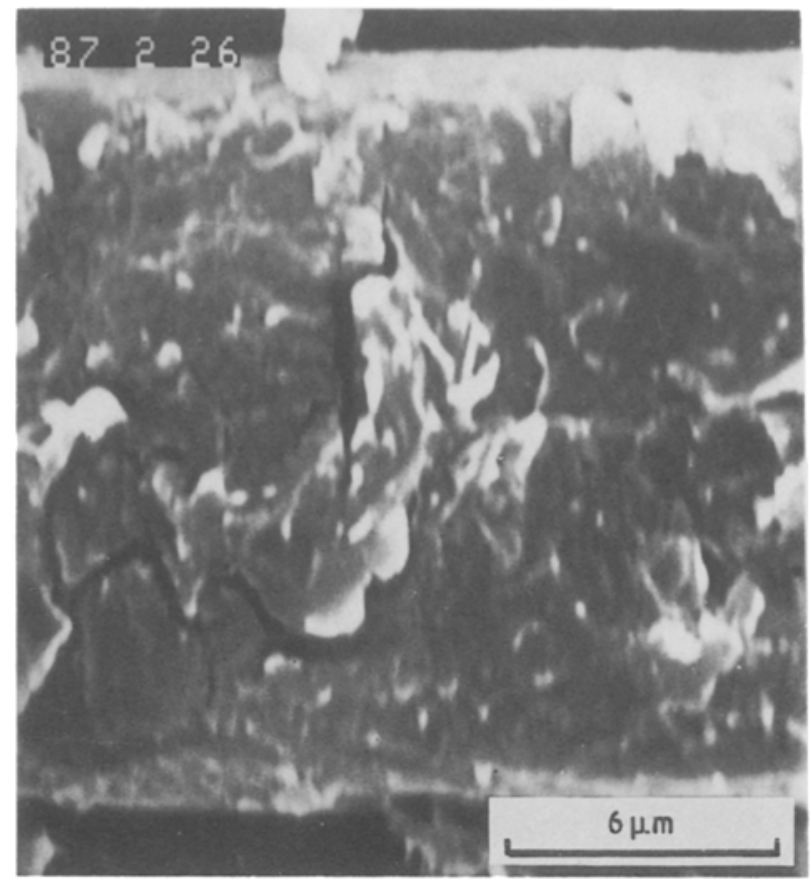

Figure 14 Longitudinal view of a bamboo-epoxy specimen showing bamboo fibre cracked by compression.

fracture surface is more uniform, with the intralaminar fracture extending throughout the entire specimen. The lateral surface of the fracture shows the source of the cracks and their subsequent propagation and enlargement (Fig. 15).

\subsection{Microstructural studies of bending and interlaminar shear fractography}

The lateral view of a test specimen fractured under bending stress shows delamination by flexure in the neutral plane and tension and compression in the upper and lower portions, respectively (Fig. 16).

Under interlaminar shear, a principal crack is

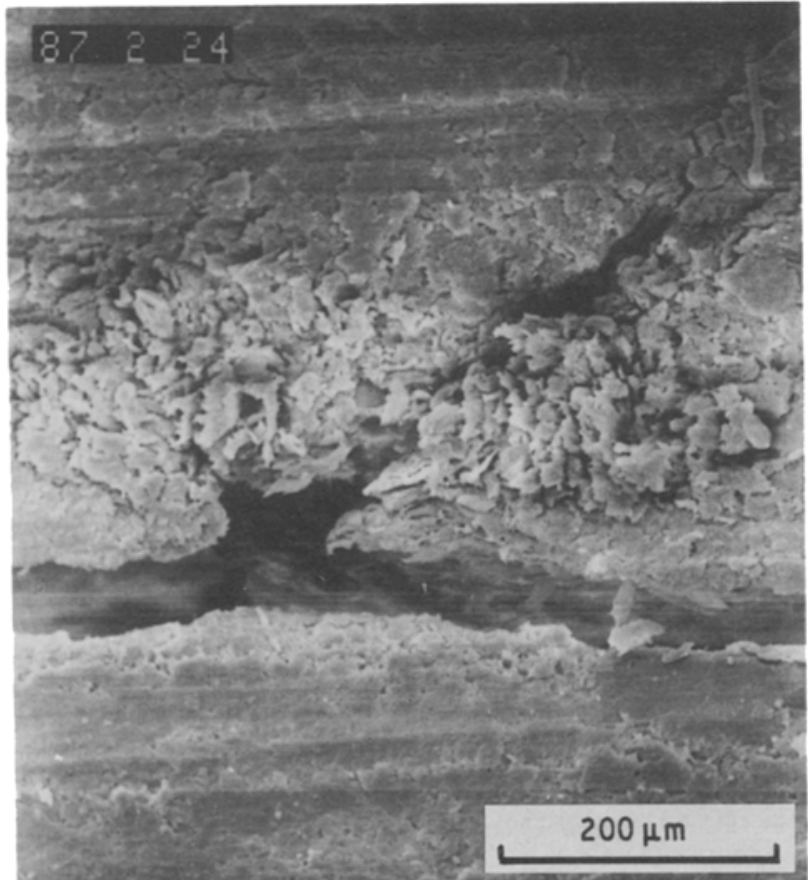

Figtre 15 Lateral surface of a compressive fracture, showing the source, propagation and enlargement of cracks. 


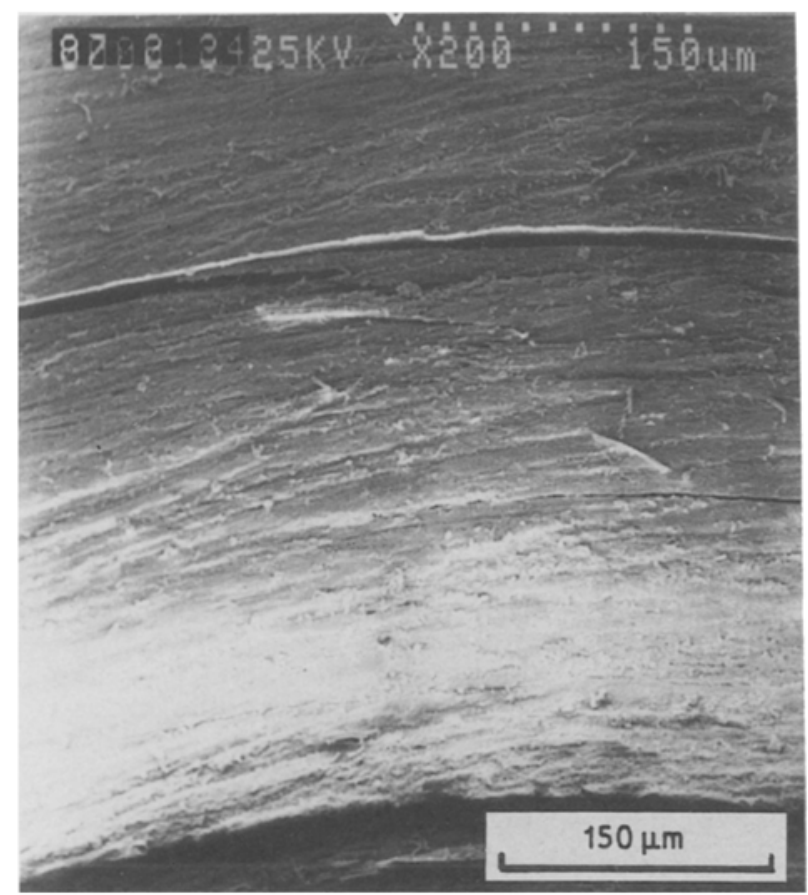

Figure 16 Lateral view of a bamboo-epoxy specimen, showing delamination by flexure in the neutral plane, and tension and compression in the upper and lower portions.

produced in the neutral plane with some secondary cracks within laminae. Bamboo fibres under tension took up load, while fibres under compression squeezed out small fragments of the epoxy matrix (Fig. 17).

\section{Concluding discussion}

The conclusions are as follows.

(1) Bamboo is a natural composite material. Bamboo reinforced epoxy composites possess specific strength superior to that of ordinary fibre-glass reinforced composites and is 3 to 4 times stronger than mild steel. Its considerable tensile, compressive and bending capabilities warrant its use for construction and other purposes.

(2) The variable tensile and compressive moduli of unidirectional bamboo-epoxy composites, the low interlaminar shear strength, the correlation between mechanical strength and lamina number, theoretical models of their behaviour and fracture modes all conform well with those of other laminated composites.

(3) Acoustic emission techniques can be applied to monitor the fracture behaviour of bamboo-epoxy. Early occurring, small amplitude emissions predict the occurrence of cracks in the epoxy, while subsequent explosive emissions indicate the occurrence of critical damage. Damage occurs rapidly thereafter, and further research in this area may allow accurate predictions of the onset of fracture and material failure.

(4) The compressive experimental designs used in the micro-analyses of fractures proved satisfactory (standard deviation $4.2 \%$ ). The dumb-bell design of test specimens for tensile stress is less satisfactory (standard deviation $8.2 \%$ ). Small test specimens with their ends clamped tightly frequently broke at the

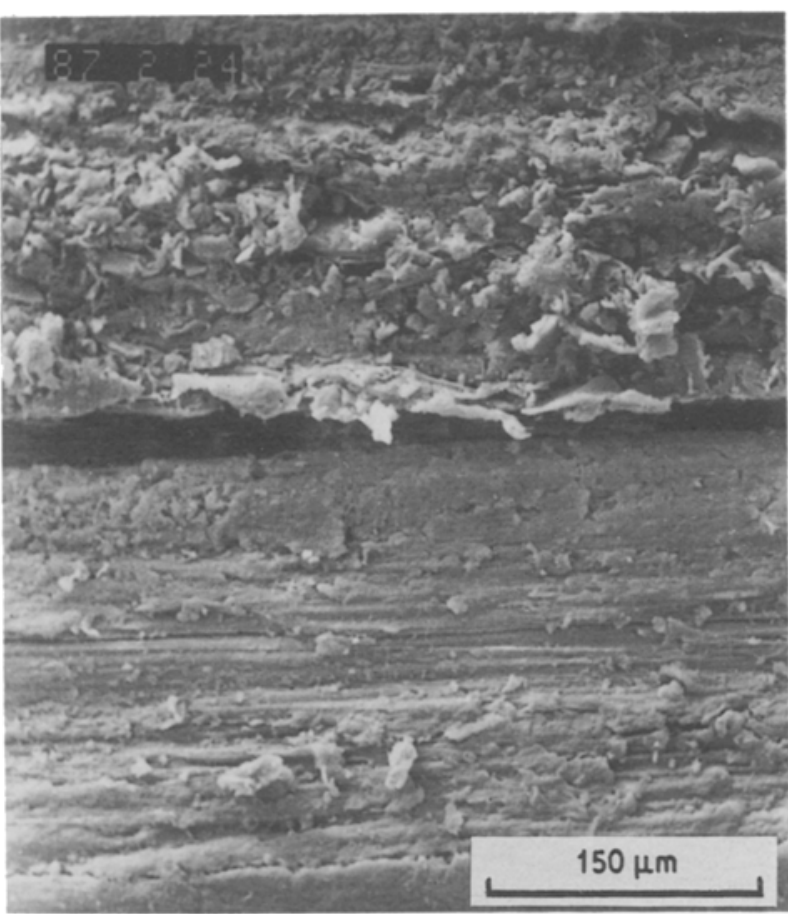

Figure 17 Lateral view of a bamboo-epoxy specimen, showing fracture induced by interlaminar shear.

ends, resulting in low values of tensile strength, and further improvement is necessary.

(5) The natural microstructure of bamboo is complex yet logical [10]. The main function of the vascular bundles and fibres is to strengthen and transmit stress, while the parenchyma form the matrix. When bamboo is pressed and embedded in epoxy, the latter infiltrates the parenchyma and intercellular spaces and further effects transmission. Thus the tensile, compressive and bending strength of the composite is enhanced. Furthermore, the composite is less susceptible to desiccation induced cracking, deformation under high relative humidity and reduction of mechanical strength caused by insect pest bioerosion.

Bamboo-epoxy composites can be produced from the abundant natural resources in Asia and South America with low manufacturing costs, and have excellent mechanical properties. The potential for its development as a building or general purpose material is immense.

\section{Acknowledgement}

The financial support of the Wideland Foundation and of the Hong Kong Polytechnic Research Committee has made this work possible.

\section{References}

1. R. M. JONES, "Mechanics of composite materials" (Kingsport Press, McGraw-Hill, 1975).

2. S. W. TSAI and H. T. HAHN, "Introduction to composites", (Technonic Publishing, Pennsylvania, 1980).

3. B. HARRIS, "High Modulus Polymers and Composites", edited by C. L. Choy (Chinese University Press, Hong Kong, 1985) p. 253.

4. J. A. MOCK, Mater, Engng 3 (1979) 60.

5. M. A. MANSUR and M, A. AZIZ, Int. J. Cem, Comp. 2 (1982) 75

6. S. C. LAKKAD and J. M. PATEL, Fibre Sci. Technol. 14 (1981) 319 
7. U. C. JINDAL, Indian For. 4 (1984) 381.

8. B. PAKOTIPRAPHA, R. P. PAMA and S. I. LEE, Imt, J. Hous. Sci. Appl. 3 (1979) 167.

9. K. M. GINSBURG and F. G. SHIN, "High Modulus Polymers and Composites" edited by C. L. Choy (Chinese University Press, Hong Kong, 1985) 433.
10. S. H. KWAN, F. G. SHIN and M. W. YIPP, Acta Materiae Compositae Sinica 4 (1987) 79.

Received 19 July

and accepted 21 November 1988 